\title{
Duration of trastuzumab in HER2-positive metastatic breast cancer after complete remission: still debatable issue?
}

\author{
Kadri Altundag ${ }^{1}$ (D)
}

Received: 13 September 2017 / Accepted: 6 October 2017 / Published online: 11 October 2017

(C) Springer Science+Business Media, LLC 2017

Dear Editor,

I wish to congratulate Niikura and colleagues for their article [1] in which they retrospectively evaluated the data of patients diagnosed with HER2-positive metastatic breast cancer who received trastuzumab for more than 2 years as the first-line treatment. They reported that some patients showed no evidence of disease after the interruption of trastuzumab therapy. As authors also stated that decision to discontinuation of maintenance, trastuzumab in this patient population is very critical issue. Favorable characteristics patients and tumor should be determined before stopping trastuzumab maintenance treatment. A subgroup of patients with HER2positive metastatic breast cancer, especially those with hormone receptor negative and truly HER2-enriched subtype and those with a structurally intact HER2 receptor who are expected be more sensitive to trastuzumab might not be good candidates for discontinuation of trastuzumab. Some case reports in the literature describe the rapid onset of symptoms soon after cessation of trastuzumab which supports the theory that the withdrawal of trastuzumab might have altered the biology of the disease and its complex interactions with the host. The objective efficacy of prolonged maintenance of trastuzumab compared with observation in HER2-positive patients achieving complete response to first-line treatment should be tested in randomized trials. However, the decision of whether trastuzumab should be discontinued or not in such patients remains strongly controversial [2, 3].

Kadri Altundag

altundag66@yahoo.com

1 MKA Breast Cancer Clinic, Tepe Prime, 06800 Cankaya, Ankara, Turkey
Compliance with ethical standards

Conflict of interest Kadri Altundag have no conflict of interest to declare.

Research involving human and animal rights This article does not contain any studies with human participants or animals performed by any of the authors.

\section{References}

1. Niikura N, Shimomura A, Fukatsu Y, Sawaki M, Ogiya R, Yasojima H, Fujisawa T, Yamamoto M, Tsuneizumi M, Kitani A, Watanabe J, Matsui A, Takahashi Y, Takashima S, Shien T, Tamura K, Saji S, Masuda N, Tokuda Y, Iwata H (2017) Durable complete response in HER2-positive breast cancer: a multicenter retrospective analysis. Breast Cancer Res Treat. doi:10.1007/ s10549-017-4489-9

2. Oguz A, Rahatli S, Altundag O, Altundag K (2015) Trastuzumab in metastatic breast cancer after complete remission: how long is enough? Med Oncol 32:211. doi:10.1007/s12032-015-0648-1

3. Hacioglu B, Akin S, Babacan T, Sever AR, Altundag K (2015) How long should we maintain anti-HER2 therapy for metastatic breast cancer patients with complete remission? Future Oncol 11:2799-2801. doi:10.2217/fon.15.165 